\title{
AVALIAÇÃO DOS EFEITOS DE HIGROSCOPICIDADE DO CLORIDRATO DE CISTEÍNA NAS CÁPSULAS DURAS
}

\author{
Caio Staph Fontes \\ Universidade Severino Sombra, Centro de Ciências da Saúde, Curso de Farmácia, \\ caiospath_fontes@yahoo.com.br \\ Luiz Fernando Chiavegatto \\ Universidade Severino Sombra, Centro de Ciências da Saúde, Curso de Farmácia, \\ lchiavegatto@gmail.com \\ Marcos A. Alves \\ Universidade Severino Sombra, Centro de Ciências da Saúde, Curso de Farmácia, \\ alves290@yahoo.com.br
}

Resumo. O presente estudo elucida uma possível interferência na integridade das cápsulas duras gelatinosas perante a absorção higroscópica de alguns princípios ativos. A l-cisteína é considerado pela literatura um fármaco muito higroscópico por este motivo foi escolhida para ser o ativo do estudo, onde foram feitas várias formulações com o seu derivado o cloridrato de cisteína anidra e excipientes que possuem características absorventes e são utilizados para suprimir a característica higroscópica do ativo e manter a cápsula sem nenhuma alteração física estrutural. Os excipientes escolhidos para o trabalho foram o amido, o dióxido de silício coloidal (Aerosil ${ }^{\circledR} 200$ ) e o carbonato de magnésio. Após manipuladas, essas cápsulas foram submetidas a 2 testes. $O$ primeiro teste analisava a estrutura física da cápsula e a sua variação de peso enquanto elas estavam dentro do recipiente original da farmácia manipuladora; o segundo analisava a estrutura física da cápsula e a variação de peso enquanto elas estavam em processo de estudo de estabilidade acelerada, nas condições de temperatura e umidade relativa do ar ambiente.

Palavras-Chave: Higroscopia; Cisteína; Excipientes; Manipulação Magistral.

\section{Evaluation of the Effects of Hygroscopicity Cysteine Hydrochloride Capsules in Hard}

\begin{abstract}
This study elucidates a possible interference with the integrity of hard gelatin capsules before the hygroscopic absorption of some active ingredients. L-cysteine is considered by the literature a very hygroscopic drug for this reason was chosen to be the active study, various formulations were made where the derivative thereof anhydrous cysteine hydrochloride and excipients that possess absorptive characteristics and are used to suppress hygroscopic character of the assets and keep the capsule without any physical structural change. The starch, colloidal silicon dioxide (Aerosil $\left.{ }^{\circledR} 200\right)$ and magnesium carbonate are the excipients work. After manipulated, these capsules undergo two tests. The first test analyzed the physical structure of the capsule and its weight change while they were in the original pharmacy container handler; the second analyzed the physical structure of the capsule and weight change while they were in the process of accelerated stability study under the conditions temperature and relative humidity environment.
\end{abstract}

Keywords: Hygroscopicity, Cysteine, Excipients, Skillful Manipulation.

Revista de Saúde, Vassouras, v. 3, n. 2, p. 4-13, jul./dez., 2012 


\section{Avaliação dos Efeitos de Higroscopicidade do Cloridrato de Cisteína nas Cápsulas Duras Caio Staph Fontes, Luiz Fernando Chiavegatto e Marcos A. Alves}

\section{Introdução}

A manipulação é uma tarefa primordial e vital no universo das farmácias magistrais. Estes processos devem ser acompanhados de perto pelo farmacêutico responsável, onde o mesmo deve avaliar criticamente a receita a ser avaliada (Ferreira et al., 2001). As cápsulas gelatinosas duras são a forma farmacêutica sólida oral de eleição na farmácia magistral. A utilização da cápsula é devida principalmente à sua versatilidade. As cápsulas permitem a veiculação de misturas de pós, líquidos, desde que não hidrofílicos, massas semissólidas e até mesmo de outras formas farmacêuticas de menor volume. Além disso, é possível preparar cápsulas com conteúdo de liberação modificada tais como, de liberação entérica e liberação lenta (Allen Jr., 2002).

Embora as cápsulas gelatinosas duras sejam relacionadas como uma forma farmacêutica simples, o desenvolvimento de formulações para as mesmas pode representar significantes desafios ao formulador. Por exemplo, a seleção dos excipientes necessários para o preenchimento da cápsula; problemas tais como compatibilidade dos ingredientes e estabilidade; mistura dos pós e homogeneidade; fluidez dos pós e lubrificação são frequentemente observados e, precisam ser levados em consideração durante o desenvolvimento das formulações (Guo et al., 2002). A maioria dos produtos preparados na forma de cápsulas gelatinosas duras consiste em uma mistura do fármaco em combinação com diversos tipos de excipientes. A escolha dos excipientes depende de vários fatores: a características e propriedades do fármaco veiculado, a dose, a solubilidade, o tamanho e forma de partículas do fármaco e o tamanho da cápsula a ser utilizada (Aulton, 2005).

Em formulações de pós para encapsulação, o fármaco e os componentes inertes precisam ser misturados de forma a assegurar uma mistura de pó homogênea para o preenchimento das cápsulas. Um cuidado especial no processo de mistura deve ser tomado para formulações com fármacos em baixa dosagem, onde a falta de homogeneidade pode resultar em graves consequências terapêuticas (Allen Jr.; Popovich and Ansel, 2005). Os fármacos encapsulados raramente são administrados isoladamente, normalmente vêm acompanhados de excipientes. Estas substâncias são produtos auxiliares diretamente envolvidas na composição das diversas formulações farmacêuticas. Embora historicamente os excipientes tenham sido considerados inertes, já que não exercem ação terapêutica ou biológica na forma farmacêutica, hoje são vistos como capazes de influenciar a velocidade e/ou a extensão da absorção de um fármaco (Aulton, 2005). O fármaco e os excipientes utilizados devem ser compatíveis entre si para gerar um produto estável, eficaz, atraente, fácil de administrar e seguro. Como alguns fármacos têm características especiais físico-químicas e de compatibilidade deve-se selecionar os excipientes adequados a eles (Ansel, Popovich and Allen, 2000).

A umidade representa um papel destacadamente negativo em preparações farmacêuticas, particularmente em formas farmacêuticas sólidas e excepcionalmente em cápsulas duras de gelatina, reconhecidamente sensíveis à sua presença. Tanto a estabilidade química como a estabilidade física de alguns ingredientes farmacêuticos ativos e do invólucro da cápsula podem ser afetados pela presença de umidade (Islam et al., 2008). A natureza higroscópica de excipientes e ingredientes ativos deve ser considerada no desenvolvimento da formulação. A utilização de uma quantidade suficiente de excipiente na formulação pode prevenir o problema (Gohil, 2002). Os excipientes absorventes diminuem a tendência dos pós em absorver a umidade proveniente de substâncias higroscópicas, minimizando o contato de partículas de pós, reduzindo desta forma a tendência à liquefação de misturas eutéticas (USP, 2008).

Deve-se empregar um tamanho de cápsula que permita a adição de, pelo menos, $50 \%$ do volume da cápsula com o excipiente, garantindo assim que o mesmo contribua efetivamente para a redução da absorção de umidade pelo fármaco. A adição de uma quantidade mínima de excipiente

Revista de Saúde, Vassouras, v. 3, n. 2, p. 4-13, jul./dez., 2012 


\section{Avaliação dos Efeitos de Higroscopicidade do Cloridrato de Cisteína nas Cápsulas Duras Caio Staph Fontes, Luiz Fernando Chiavegatto e Marcos A. Alves}

não seria capaz de evitar eficientemente a absorção de umidade (Tabela 1). Além do uso de um diluente apropriado, o emprego no excipiente de um agente dessecante, como o dióxido de silício coloidal (Aerosilß 200), também contribui na diminuição da higroscopia (Ferreira, 2009). O controle do percentual de umidade relativa, no ambiente do laboratório pode evitar vários problemas de estabilidade com a manipulação de fármacos higroscópicos. A umidade relativa (UR), no ambiente de manipulação de cápsulas contendo fármacos higroscópicos, deve ser baixa, situada entre 30 a $45 \%$ de UR (USP, 2008) ou, preferencialmente, um pouco menos, entre 20-25\% (Islam et al., 2008).

Tabela 1: Relação de excipientes com propriedades absorventes que podem ser utilizados para aumentar a compatibilidade de misturas eutéticas, substâncias deliquescentes e higroscópicas

\begin{tabular}{|l|l|}
\hline \multirow{5}{*}{ Efetivos } & Carbonato de magnésio \\
\cline { 2 - 2 } Menos efetivo & Caolim \\
\cline { 2 - 2 } & Óxido de magnésio leve \\
\hline Relativamente inefetivo & Óxido de magnésio pesado \\
\cline { 2 - 2 } & Fasfato de cálcio tribásico \\
\cline { 2 - 2 } & Sílica gel (dióxido de silício coloidal $=$ Aerosil $\left.^{\circledR} 200\right)$ \\
\cline { 2 - 2 } & Lactose \\
\cline { 2 - 2 } & Amido \\
\hline
\end{tabular}

Fonte: USP, 2005.

A cisteína é um aminoácido sulfurado, sintetizado a partir da metionina através da via de transulfuração durante a vida adulta. Metaboliza-se a piruvato e sulfato inorgânico e, é a fonte de sulfato inorgânico que se introduz nos polissacarídeos complexos e outras substâncias estruturais do organismo (P. R. Vade-mécum Brasil 2008-09). É empregada como suplemento alimentar e em processos como desintoxicação e eliminação de radicais livres, proteção das células hepáticas e cerebrais contra o álcool e o tabaco, fluidificação do muco do trato respiratório e remoção do cobre do organismo (Batistuzzo; Itaya and Eto, 2010).

\section{Metodologia}

Foram doadas 450 cápsulas duras de l-cisteína pela Farmácia de Manipulação Gaia Alopatia e Homeopatia, situada na praça XV de novembro, $n^{\circ} 131$, centro, Valença, RJ. Sendo essas 450 cápsulas manipuladas para fins de pesquisa utilizando os laboratórios e manipuladores da mesma. Os excipientes foram escolhidos de acordo com a sugestão da USP (2005), para excipientes com propriedades absorventes, como o carbonato de magnésio, dióxido de silício coloidal e o amido. E em seguida manipulados de acordo com a Tabela 2.

Revista de Saúde, Vassouras, v. 3, n. 2, p. 4-13, jul./dez., 2012 
Tabela 2: Amostras para o teste de estabilidade das cápsulas

\begin{tabular}{|c|c|c|c|c|}
\hline & & & & \\
\hline AMOSTRA & DIVISÕES & $\begin{array}{c}\mathrm{N}^{\circ} \mathrm{DE} \\
\text { CÁPSULAS }\end{array}$ & PRINCÍPIO ATIVO & EXCIPIENTES \\
\hline & A & 30 & $250 \mathrm{mg}$ de cloridrato de & \\
\hline 01 & B & 30 & $\begin{array}{l}\text { cisteina equivalente a } \\
192,3 \mathrm{mg} \text { de } l \text {-cisteína }\end{array}$ & Amido Q.S.P. \\
\hline & $\mathrm{C}$ & 30 & & \\
\hline & A & 30 & $250 \mathrm{mg}$ de cloridrato de & Dióxido de silício \\
\hline 02 & B & 30 & $192,3 \mathrm{mg}$ de $l$-cisteína & amido Q.S.P. \\
\hline & $\mathrm{C}$ & 30 & & \\
\hline & A & 30 & $250 \mathrm{mg}$ de cloridrato de & Dióxido de silício \\
\hline 03 & B & 30 & $192,3 \mathrm{mg}$ de $l$-cisteína & Q.S.P. \\
\hline & $\mathrm{C}$ & 30 & & \\
\hline & A & 30 & $250 \mathrm{mg}$ de cloridrato de & Carbonato de \\
\hline 04 & B & 30 & $192,3 \mathrm{mg}$ de $l$-cisteína & \\
\hline & $\mathrm{C}$ & 30 & & \\
\hline & A & 30 & $250 \mathrm{mg}$ de cloridrato de & Dióxido de silício \\
\hline 05 & B & 30 & $192,3 \mathrm{mg}$ de $l$-cisteína & Carbonato de \\
\hline & $\mathrm{C}$ & 30 & & \\
\hline
\end{tabular}

Fonte: Dados da Pesquisa

As cápsulas foram manipuladas no dia 15/09/2012 e permaneceram durante 11 dias dentro do recipiente original, da farmácia doadora, que consiste em um recipiente plástico R-60 com dispositivo de armazenagem de sílica aderido a tampa, período no qual foi analisada sua estrutura física visível a olho nu e pesadas diariamente em balança semi analítica GEHAKA BG200 com o auxílio de uma placa de petri e uma pinça. Em seguida, as cápsulas foram encaminhadas ao teste de estudo de estabilidade acelerado que consiste em acelerar a degradação química e/ou mudança física ou microbiológica de um produto em condições forçadas de armazenamento e avaliar o impacto a exposições fora daquelas determinadas no rótulo do produto. As condições utilizadas foram: temperatura e umidade relativa do ar ambiente; permanecendo nesse teste durante 30 dias (do período de 26/09/2012 a 26/10/2012). Foram pesadas diariamente em balança de precisão (com o auxílio de uma placa de Petri e uma pinça) e, foram analisadas quanto a sua estrutura física visível a olho nu. 


\section{Avaliação dos Efeitos de Higroscopicidade do Cloridrato de Cisteína nas Cápsulas Duras \\ Caio Staph Fontes, Luiz Fernando Chiavegatto e Marcos A. Alves}

\section{Resultados}

A partir da observação realizada durante os 11 dias após a data de fabricação das capsulas de $l$ cisteína que permaneciam dentro dos invólucros originais, observou-se que não ocorreu nenhuma alteração estrutural física perceptível a olho nu e não houve nenhuma variação de peso em nenhuma das amostras. Em seguida, observou-se o comportamento das mesmas capsulas durante o intervalo de 26/09/2012 a 26/10/2012 em processo de estudo de estabilidade acelerada, em condições de temperatura e umidade relativa do ar ambiente.

As amostras 1A, 1B, 1C, 2A, 2B, 2C, 3A, 3B e 3C não sofreram nenhuma alteração estrutural física perceptível à olho nu na cápsula e apresentaram uma variação de peso descrito na Tabela 3.

Tabela 3: Variação do peso das cápsulas 1A, 1B, 1C, 2A, 2B, 2C, 3A, 3B e 3C no período de 26/09/2012 a $26 / 10 / 2012$

\begin{tabular}{|c|c|c|c|c|c|c|c|}
\hline AMOSTRA & $\begin{array}{l}\text { DIVI- } \\
\text { SÕES }\end{array}$ & $\begin{array}{l}\mathrm{N}^{\circ} \quad \mathrm{DE} \\
\text { CÁPSU- } \\
\text { LAS }\end{array}$ & $\begin{array}{l}\text { PESO } \\
\text { TOTAL } \\
\text { INICIAL } \\
(\mathrm{g})\end{array}$ & $\begin{array}{l}\text { PESO } \\
\text { MÉDIO } \\
\text { INICIAL } \\
\text { (g) }\end{array}$ & $\begin{array}{l}\text { PESO } \\
\text { TOTAL } \\
\text { FINAL } \\
\text { (g) }\end{array}$ & $\begin{array}{l}\text { PESO } \\
\text { MÉDIO } \\
\text { FINAL } \\
\text { (g) }\end{array}$ & $\begin{array}{l}\text { MÉDIA DE } \\
\text { VARIAÇÃO } \\
(\%)\end{array}$ \\
\hline \multirow{3}{*}{01} & A & 30 & 22,038 & 0,7346 & 22,776 & 0,7592 & 3,34 \\
\hline & B & 30 & 22,002 & 0,7334 & 22,738 & 0,7579 & 3,34 \\
\hline & $\mathrm{C}$ & 30 & 22,104 & 0,7368 & 22,747 & 0,7582 & 2,90 \\
\hline \multirow{3}{*}{02} & A & 30 & 22,689 & 0,7563 & 23,392 & 0,7797 & 3,09 \\
\hline & B & 30 & 22,647 & 0,7549 & 23,362 & 0,7787 & 3,15 \\
\hline & $\mathrm{C}$ & 30 & 22,710 & 0,7570 & 23,464 & 0,7821 & 3,32 \\
\hline \multirow{3}{*}{03} & A & 30 & 23,376 & 0,7792 & 24,218 & 0,8072 & 3,60 \\
\hline & B & 30 & 23,312 & 0,7770 & 24,271 & 0,8090 & 4,11 \\
\hline & $\mathrm{C}$ & 30 & 23,349 & 0,7783 & 24,200 & 0,8066 & 3,64 \\
\hline
\end{tabular}

Fonte: Dados da Pesquisa

As amostras 4A, 4B, 4C, 5A, 5B e 5C sofreram alteração estrutural física perceptível, a olho nu, na cápsula no dia 09/10/2012, impossibilitando a pesagem das mesmas. O processo de avaliação da variação de peso das cápsulas das amostras 4A, 4B, 4C, 5A, 5B e 5C no dia 08/10/2012 foram interrompidas. As alterações de peso das cápsulas 4A, 4B, 4C, 5A, 5B e 5C (no período de 26/09/2012 a 08/10/2012) variam de acordo com a Tabela 4.

Revista de Saúde, Vassouras, v. 3, n. 2, p. 4-13, jul./dez., 2012 
Avaliação dos Efeitos de Higroscopicidade do Cloridrato de Cisteína nas Cápsulas Duras

Caio Staph Fontes, Luiz Fernando Chiavegatto e Marcos A. Alves

Tabela 4: Variação do peso das cápsulas 4A, 4B, 4C, 5A, 5B e 5C no período de 26/09/2012 à 08/10/2012.

\begin{tabular}{|c|c|c|l|l|l|l|l|}
\hline AMOSTRA & DIVI- & $\begin{array}{c}\text { N DE } \\
\text { CÁPSU- } \\
\text { SÕES } \\
\text { LAS }\end{array}$ & $\begin{array}{l}\text { PESO } \\
\text { TOTAL } \\
\text { INICIAL } \\
(\mathrm{g})\end{array}$ & $\begin{array}{l}\text { PESO } \\
\text { MÉDIO } \\
\text { INICIAL } \\
(\mathrm{g})\end{array}$ & $\begin{array}{l}\text { PESO } \\
\text { TOTAL } \\
\text { FINAL } \\
(\mathrm{g})\end{array}$ & $\begin{array}{l}\text { PESO } \\
\text { MÉDIO } \\
\text { FINAL } \\
(\mathrm{g})\end{array}$ & $\begin{array}{l}\text { MÉDIA DE } \\
\text { VARIAÇÃO } \\
(\%)\end{array}$ \\
\hline \multirow{3}{*}{04} & $\mathrm{~A}$ & 30 & 17,919 & 0,5973 & 19,772 & 0,6590 & 10,34 \\
\cline { 2 - 9 } & $\mathrm{B}$ & 30 & 18,013 & 0,6004 & 20,254 & 0,6751 & 12,44 \\
\hline \multirow{3}{*}{05} & $\mathrm{C}$ & 30 & 17,979 & 0,5993 & 19,449 & 0,6483 & 8,17 \\
\cline { 2 - 9 } & $\mathrm{A}$ & 30 & 16,944 & 0,5648 & 20,076 & 0,6692 & 18,48 \\
\cline { 2 - 9 } & $\mathrm{C}$ & 30 & 16,873 & 0,5624 & 19,620 & 0,6540 & 16,28 \\
\hline
\end{tabular}

Fonte: Dados da Pesquisa

Grafico 1: Variaça de peso das cäpsulas.em relaçio ao II de dias ile observacio

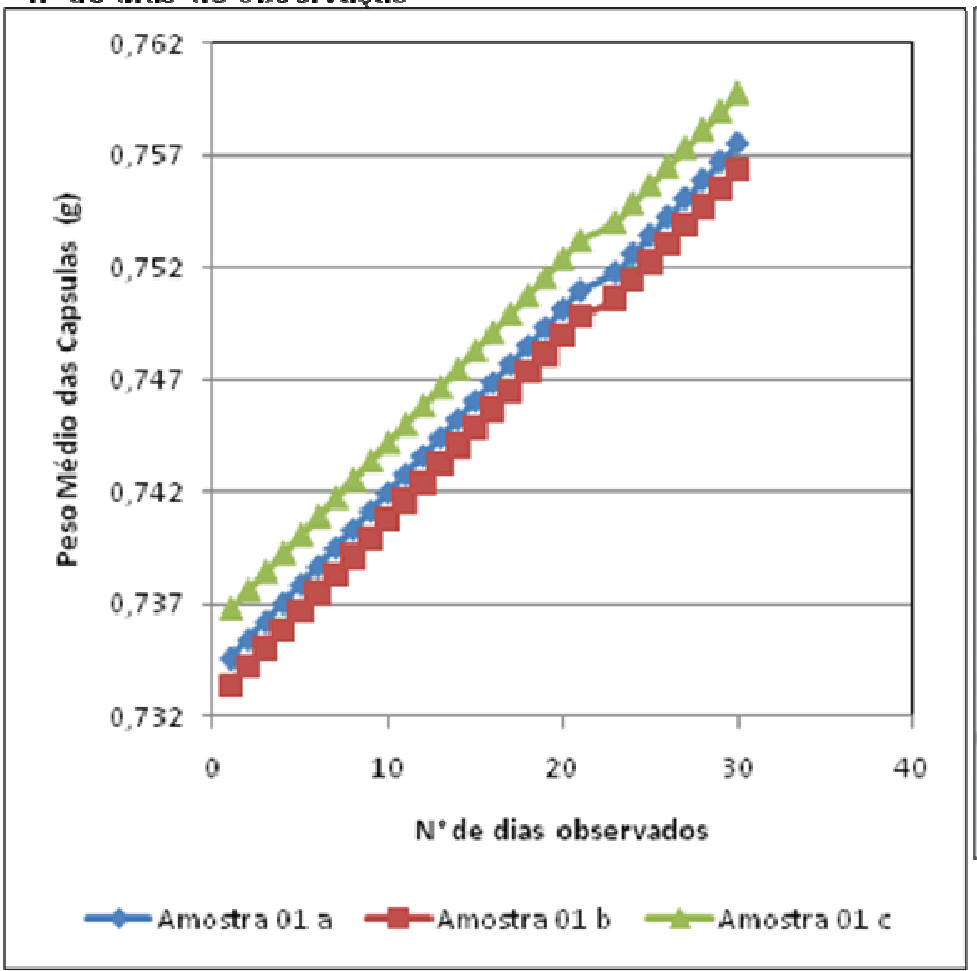

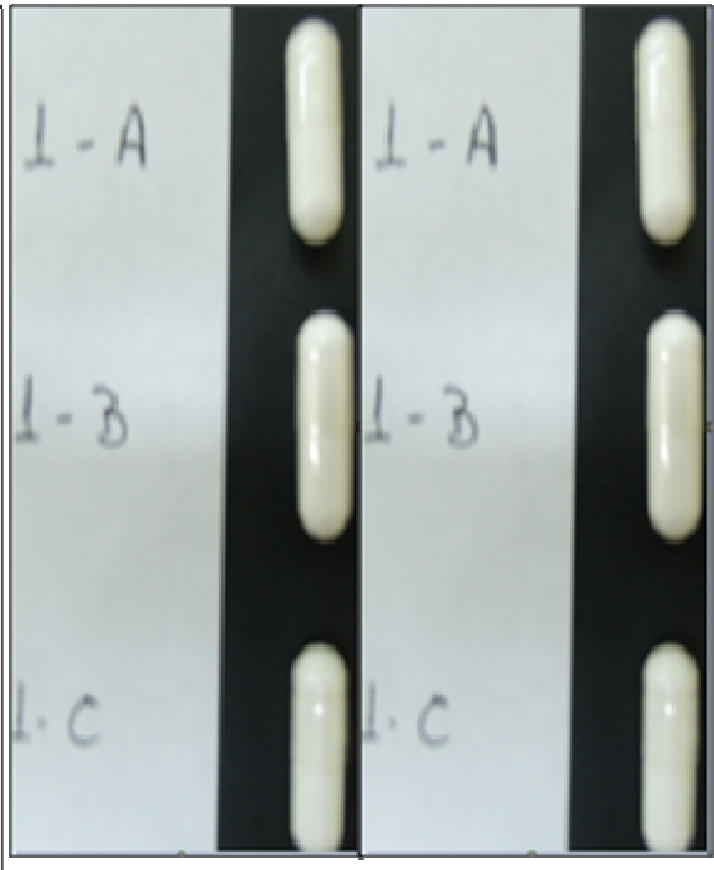

Figu a 1: Amostia $1 \mathrm{em} 26: 09: 12$ (es quer dal Amostra 1 em $26: 10: 12$ (direita)

Fonte: Dados da Pesquisa

Revista de Saúde, Vassouras, v. 3, n. 2, p. 4-13, jul./dez., 2012 


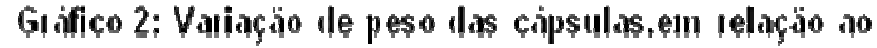
$n^{*}$ de dias de observaçäo

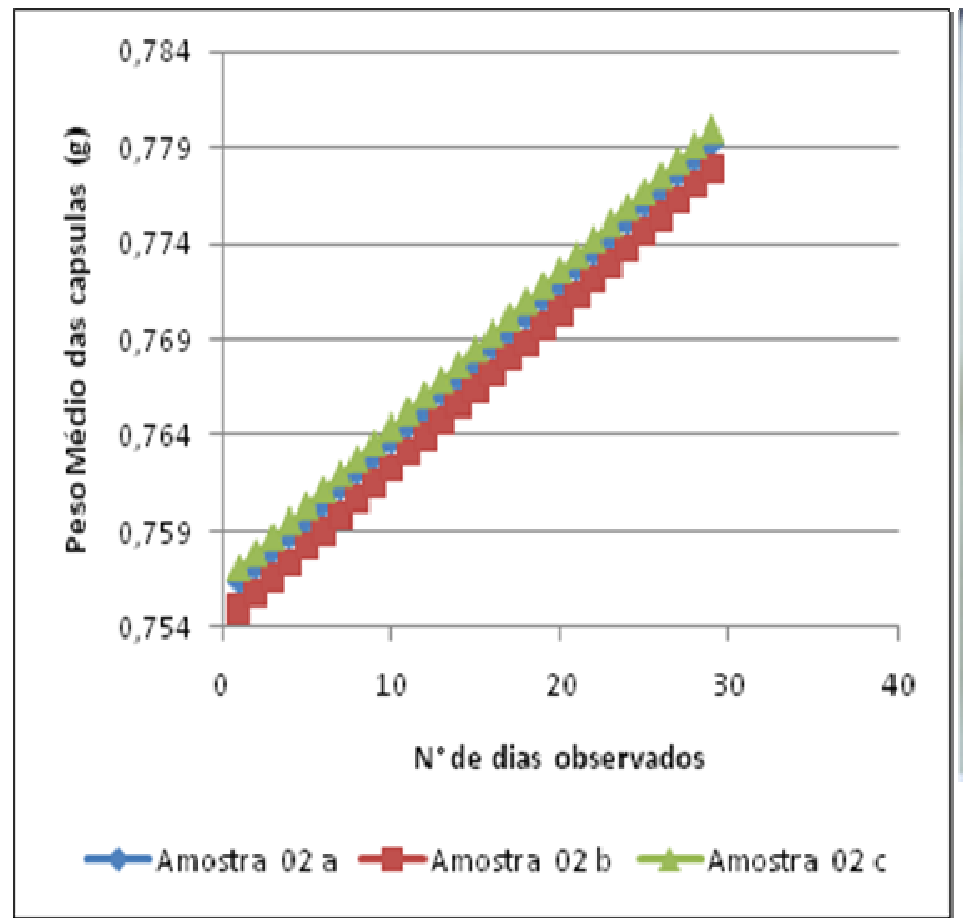

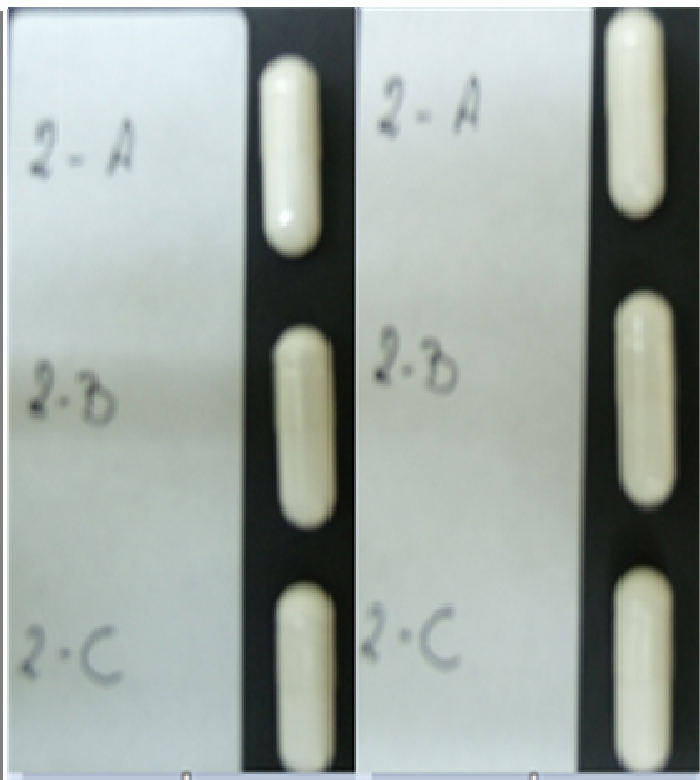

Figulat 2: Amostra 2 em 26:09:12ies querda) Amostia 2 ell $26: 10: 12$ (4li eital

Fonte: Dados da Pesquisa

Gráfico 3: Valiaçäo de pes.o das cáps ullas,em relaçälo ao $\mathrm{n}^{*}$ de dias de observaçäo

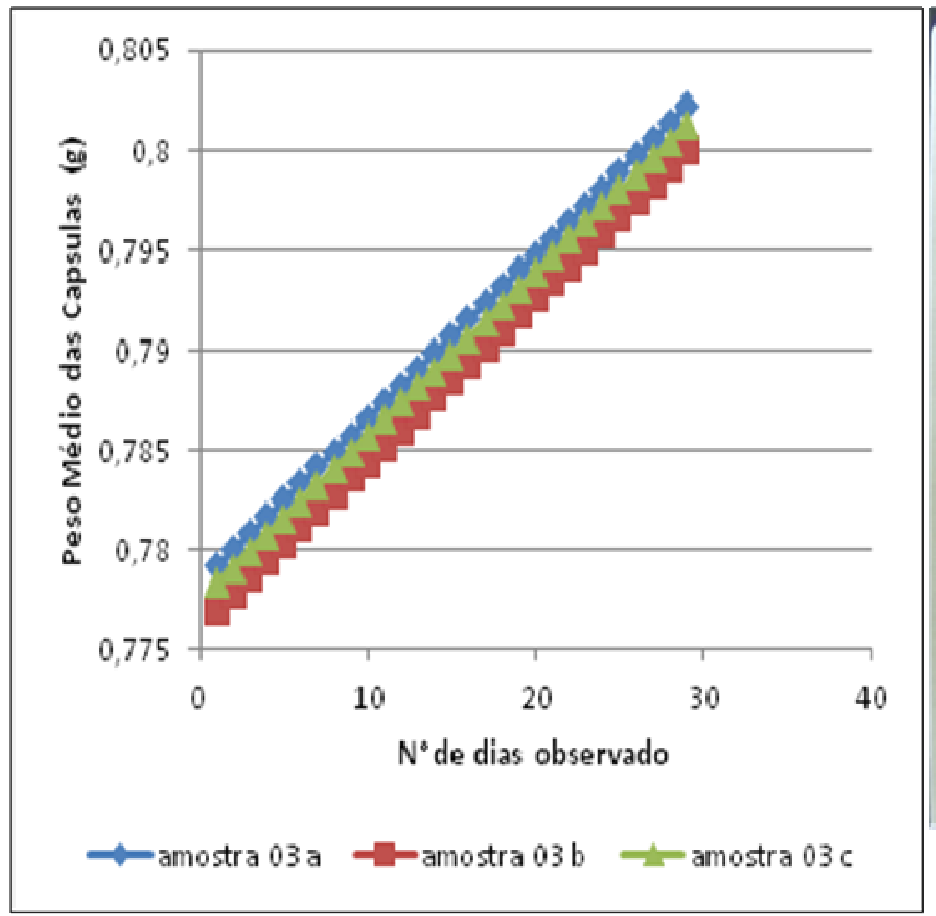

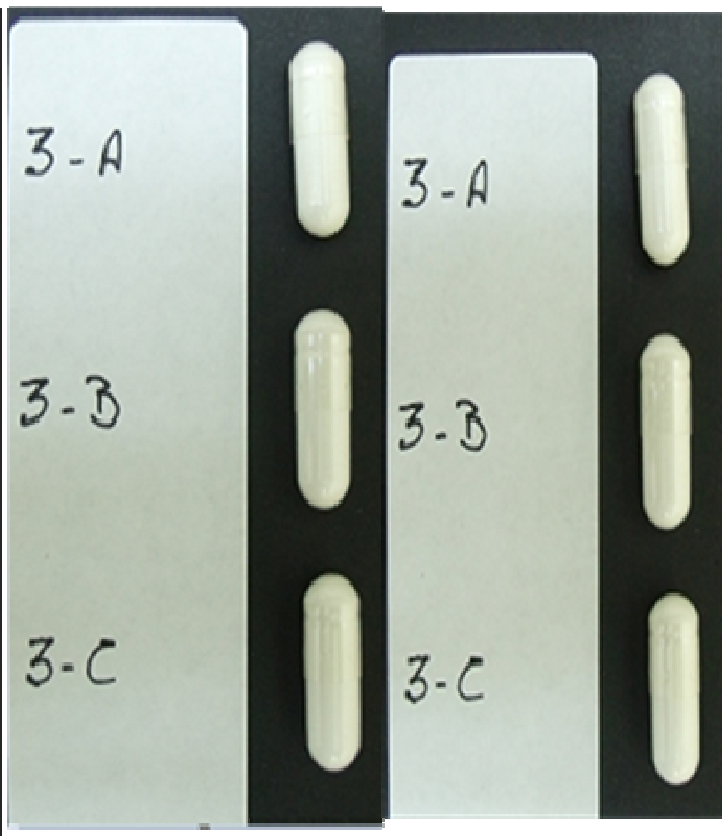

Figut a 3: Amostia 3 em 26:09 12/esquerd al Amostra 3 en $26 \cdot 10: 12$ (dir eita)

Fonte: Dados da Pesquisa

Revista de Saúde, Vassouras, v. 3, n. 2, p. 4-13, jul./dez., 2012 
Grifico 4: Variaçäo de peso dlas cápsulas,em relaçäo ào ${ }^{2}$ de dias de observaçăo
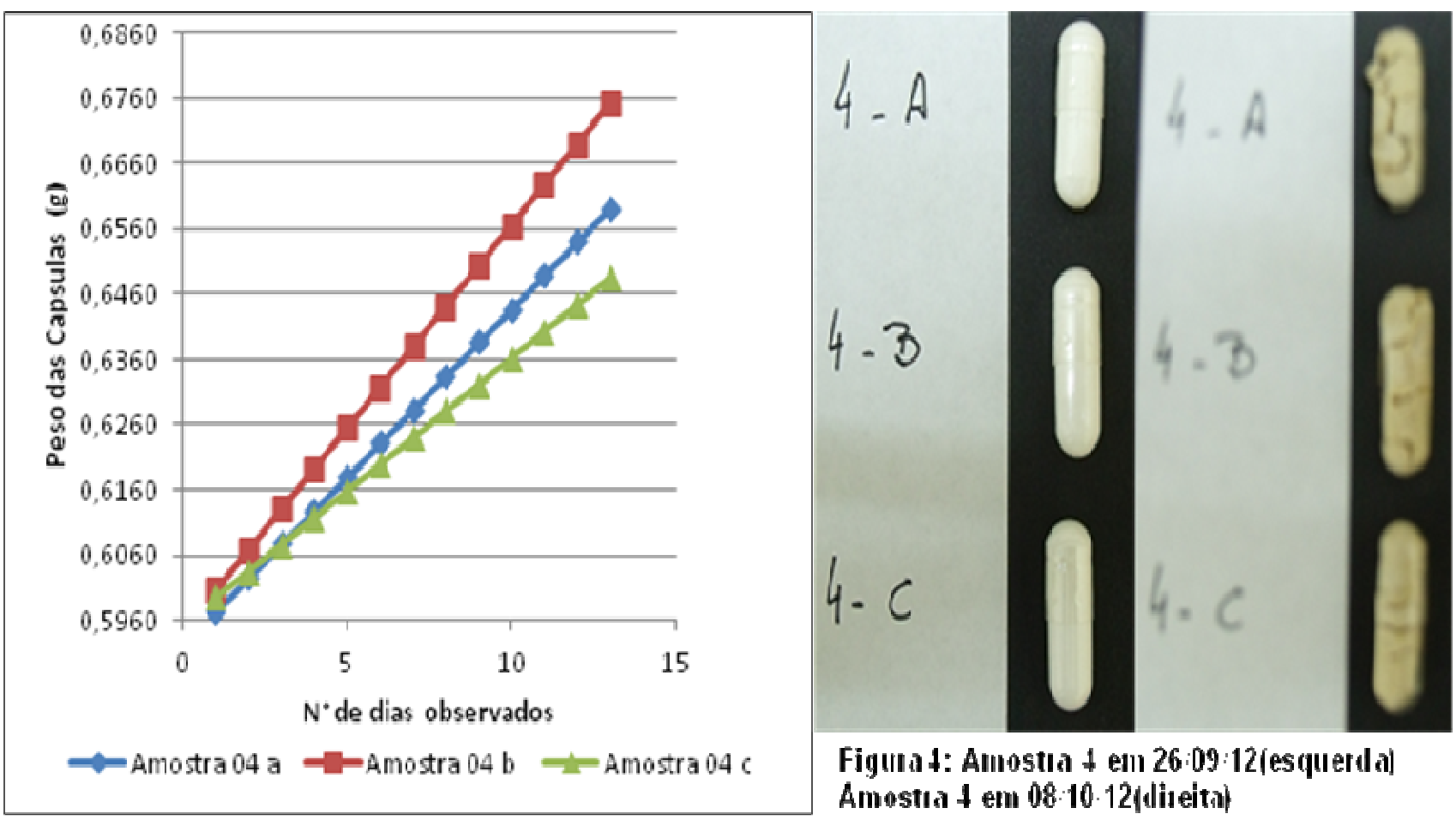

Figuna 4: Amostra \& em 26:09:12 (esquerta) Amostıa 4 em 08:10.12/dìeita)

Fonte: Dados da Pesquisa

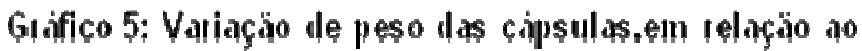
$n^{2}$ de dias vle obselvaçáo

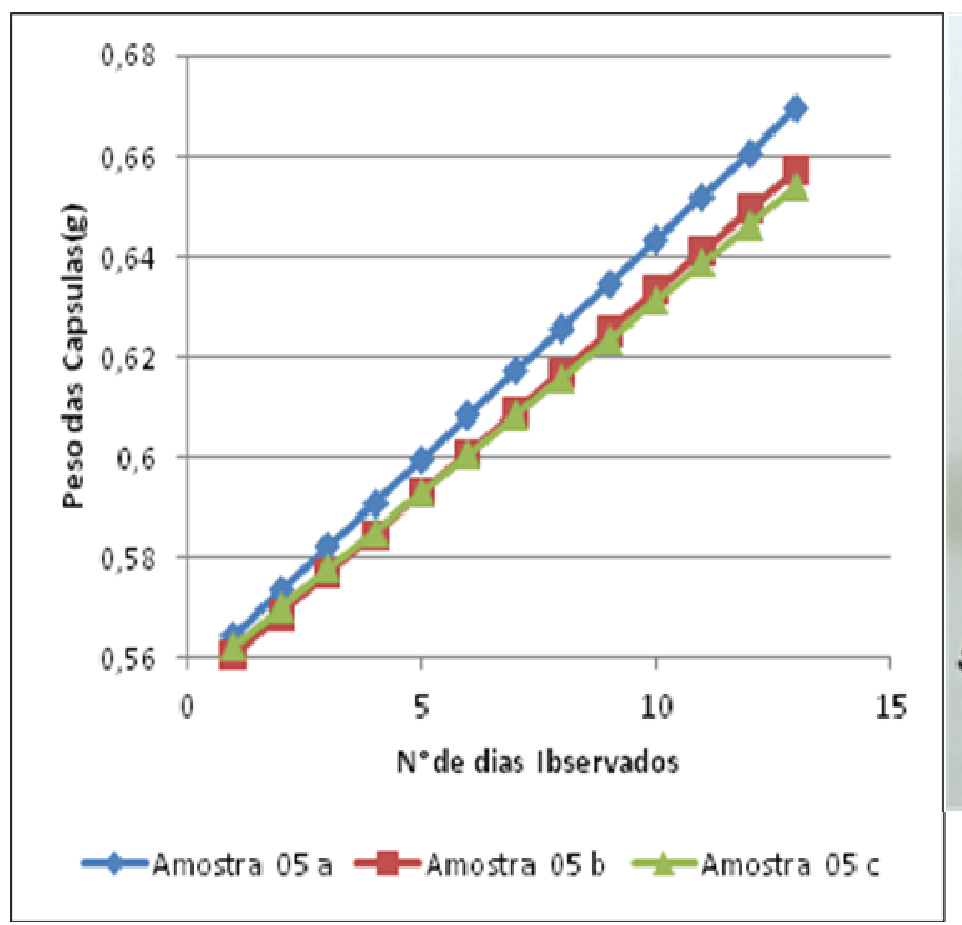

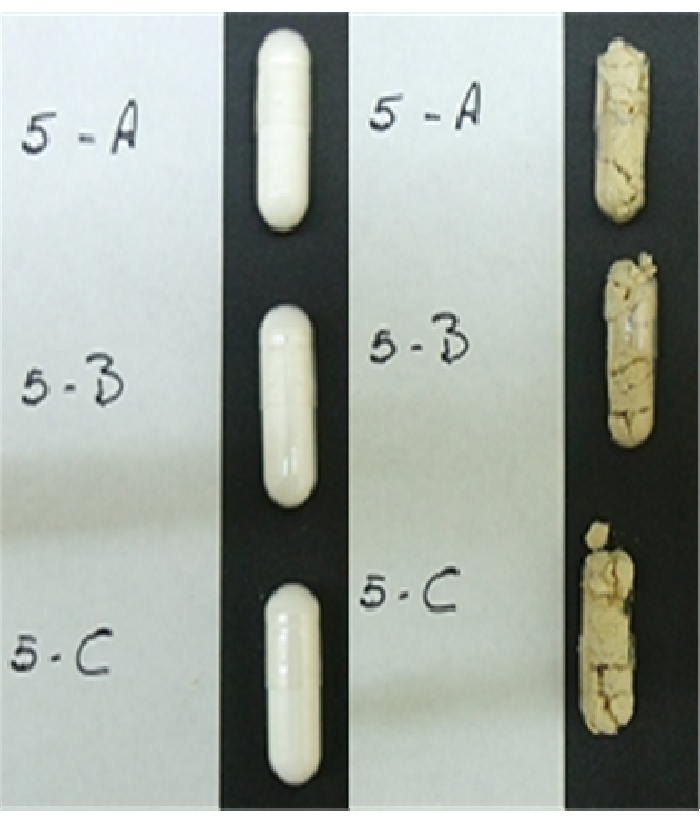

Figura 5: Amostia 5 em 26:09:12ies (puen da) Amostia 5 em 08:10:12 (dir eita)

Fonte: Dados da Pesquisa

Revista de Saúde, Vassouras, v. 3, n. 2, p. 4-13, jul./dez., 2012 


\section{Conclusão}

Segundo os resultados obtidos todas as amostras que estavam no recipiente plástico, foram protegidas evidenciando que além do excipiente com propriedades absorventes o invólucro é o elemento necessário para a proteção da mistura, reforçando a ideia de que além da proteção física que o recipiente proporciona, o dispositivo de sílica que fica aderido a tampa do recipiente não permitiu que a umidade chegasse as cápsulas, fazendo com que não ocorresse nenhuma alteração.

$\mathrm{Na}$ medida em que as cápsulas foram colocadas em processo de estudo de estabilidade acelerada, fora da proteção do recipiente original e expostas a temperatura e umidade relativa do ar ambiente verificaram-se que somente a mistura que tinha amido como excipiente se mostrou segura. Isso pode ser explicado, como afirma Singh et al. (2002), pelo fato de que o amido de milho contém uma substância estabilizante chamado hemetileno tetramina que pode com o tempo interagir com a gelatina da cápsula, formando ligações cruzadas e reduzindo a dissolução do invólucro. Assim sendo as amostras que continham o amido como excipiente (amostras 1, 2 e 3) não sofreram nenhuma alteração na estrutura física visível na cápsula.

Os excipientes dióxido de silício coloidal e carbonato de magnésio são sugeridos pela USP (2005), como excipientes com propriedades absorventes para a manipulação de cápsulas duras gelatinosas, Porém sua eficiência parece estar dependente também da proteção oferecida pela embalagem primária conforme demonstrado nesse trabalho. Este trabalho não pretende ser conclusivo, mas sim ponto de partida para outras verificações a respeito do encapsulamento de substancias higroscópicas e a escolha correta de seu excipiente.

\section{Referências}

Allen Jr., L. V. The Art, Science and Technology of Pharmaceutical Compounding. $2^{\text {nd }}$ ed. Washington:AphA, 2002. p.133-159.

Allen Jr., L. V.; Popovich, N. G.; Ansel, H. C. Anse'ls Pharmaceutical Dosage Forms and Drug Delivery Systems. $8^{\text {th }}$ edition. Baltimore: Lippincott Williams \& Wilkins, 2005. Chapter 7, p.204- 226.

Ansel, H. C; Popovich, N. G.; Allen, L. V. Farmacotécnica: Formas Farmacêuticas \& Sistemas de Liberação de Fármacos. 6 ed. Premier, 2000.

Aulton, M. E. Delineamento de formas farmacêuticas. 2. ed. Porto Alegre: Artmed, 2005. p. 256262 e 453-476.

Batistuzzo, J. A. O.; Itaya, M.; Eto, Y. Formulário Médico-Farmacêutico. $1^{\text {o }}$ Ed. São Paulo: Pharmabooks Editora, 2010.

Ferreira, A. O. Artigo Técnico: Manipulação de cápsulas contendo fármacos higroscópicos, 2009.

Ferreira, A. O. et al. Guia Prático da Farmácia Magistral. 2a edição. Juiz de Fora: Pharmabooks, 2001.

Gohil, U.C. Investigations into the Filling Properties of Powder Mixtures into Hard Shell Capsules. $\mathrm{PhD}$ Thesis, University of London, 2002. 184: 202-212. 
Guo, M.; Kaira, G.; Wilson, W.; Peng, Y.; Augsburger, L. L. A Prototype Intelligent Hybrid System for Hard Gelatin Capsule Formulation Development. Pharmaceutical Technology, 2002. p. 44-60.

Islam, S. M. A. et al. Study of Moisture Absorption by Ranitidine Hydrochloride: Effect of \% RH,Excipients, Dosage Forms and Packing Materials. J. Pharm.Sci. 7(1): 59-64, 2008.

Singh, S.; Rama Rao, K. V.; Venugopal, K.; Manikandan, R. Alteration in Dissolution Characteristics of Gelatin-Containing Formulations. Pharmaceutical Technology April 2002, p. $36-58$.

USP Pharmacists' Pharmacopeia. $1^{\text {st }}$ ed. Washington: The United States Pharmacopeial Convention, 2005. p. 775-782.

USP Pharmacists' Pharmacopeia. 2nd ed. Washington: The United States Pharmacopeial Convention, 2008. 